\title{
RESENHA DO LIVRO “SOCIEDADE DO CANSAÇO”
}

\author{
Lucas Lopes Pinto ${ }^{1}$ \\ Thelma Pontes Borges ${ }^{2}$ \\ Adimilson Renato da Silva ${ }^{3}$
}

HAN, Byung-Chul. Sociedade do cansaço. Trad. Enio Paulo Giachini. Petrópolis - RJ: Vozes, 2015. 80 p.

Byung-Chul Han, autor da obra Sociedade do Cansaço, tradução de Enio Paulo Giachini, Petrópolis - RJ, editora: Vozes, ano de 2015. Filósofo sul-coreano consolidou sua carreira na Alemanha, cursou Filosofia na Universidade de Friburgo e Literatura Alemã, além de Teologia na Universidade de Munique. Atua como professor de Filosofia e Estudos Culturais na Universidade de Berlim e autor de diversos livros como "Sociedade Paliativa" e "Sociedade da Transparência".

Este escrito será uma resenha do livro em questão que apresenta o sujeito da sociedade atual como sujeito do desempenho, sublinhando o excesso de sua positividade e de sua superprodução laboral que, consequentemente, emerge uma era de doenças neurais e do cansaço. A obra esta dividida em sete capítulos: A violência neuronal; Além da sociedade disciplinar; $O$ tédio profundo; Vita activa; Pedagogia do ver; O caso Bartleby e Sociedade do cansaço. Nota-se que existe

${ }^{\mathrm{I}}$ Graduação em Letras pela Universidade Estadual do Pará (UEPA) e Pedagogia pela Universidade Pitágoras (UNOPAR). Especialização em Metodologias do ensino da Língua Portuguesa e Literatura na Educação Básica pela Universidade Pitágoras (UNOPAR). Mestrando e participante e membro do "Grupo de Estudos e Pesquisa em Demandas Populares e Dinâmicas Regionais" (PPGDire) da Universidade Federal do Tocantins - UFT.

${ }^{2}$ Graduação em Psicologia pela Universidade Estadual Paulista Júlio de Mesquita Filho/UNESP (I999), mestrado em Educação pela Universidade Estadual de Campinas/UNICAMP (2003), é doutora em Psicologia Escolar e do Desenvolvimento Humano pela Universidade de São Paulo/USP (2015) e tem pós-doutorado pelo Programa de Desenvolvimento Sustentável dos Trópicos Úmidos pela Universidade Federal do Pará/UFPA (2020). Atualmente é professor adjunta III (campus de Araguaína) da Fundação Universidade Federal do Tocantins, trabalha no colegiado do curso de Letras e do curso de Mestrado em Demandas Populares e Dinâmicas Regionais. Tem experiência na área de Psicologia com ênfase em desenvolvimento humano e populações vulneráveis. Foi uma das responsáveis pela idealização, escrita e submissão do Mestrado em Demandas Populares e Dinâmicas Regionais. ${ }^{3}$ Doutorado em Ciências Sociais pela Universidade do Vale do Rio dos Sinos, Brasil(20r9) Professor de Sociologia do Instituto Federal de Educação, Ciência e Tecnologia do Tocantins, Brasil . 
um aparelhamento de estudos e análises sociais de autores como Friedrich Nietzsche (1967), Hannah Arendt (1981) e Michel Foucault (1987), que promovem discursões acerca da transição e de construção de uma identidade sociocultural para composição dos indivíduos contemporâneos, ou seja, sujeitos mergulhados numa sociedade capitalista que deu como extinto a alteridade e diversidade, cedendo lugar ao individualismo e ao narcisismo.

Doravante, a discussão origina-se com uma análise dos aspectos de violências de outrora e da época atual. Por conseguinte, cita o distanciamento e a mudança do paradigma imunológico, que é a formação do adversário da sociedade da disciplina para o paradigma do desempenho, sociedade do cansaço. Dessa forma, trás evidência de locomoção da situação-problema: o individuo não se enxerga mais no outro, mas apresenta-se no próprio sujeito.

Assim, assemelha-se com a sociedade do controle, no qual o olhar alheio delimitava os comportamentos, só que agora é o auto-olhar que delineia e determina. Destarte, sublinha-se uma sociedade que produz de maneira demasiada, buscando o máximo de seu desempenho laboral, tornando-se vítima de sim mesma. Tendo como resultado dessa busca, o nascimento de uma sociedade do cansaço, vacante, depressiva, doente e escrava de sim mesma, sequelas de um vazio nessa era digital e solitária.

Nesta era neoliberal, em que se busca perfeição, os sujeitos são cobrados para produzir mais, para fins quantitativos com sentimentos de confiança e positividade ao extremo. Esse comportamento social tem obtido resultados incoerentes com as atitudes individuas em querese dar, aparecer e produzir para uma sociedade que cobra muito. Diante disso Han (2015) diz que todos esses esforços têm desencadeado doenças psicológicas, distúrbios, perturbações, ansiedade, disfunções e depressões. Segundo Han, "o cansaço do esgotamento não é um cansaço da potência positiva. Ele nos incapacita de fazer qualquer coisa” (HAN, 2015, p. 76).

No mundo do século XXI, novas doenças começaram aparecer no mundo pós-moderno, uma crise neuronal em ascensão, "depressão, transtorne de déficit de atenção com síndrome de hiperatividade, transtorno de personalidade” (HAN, 2015, p. 8). Desse modo, essas novas enfermidades podem estar relacionadas com excesso de positividade, que a todo instante o individuo é convocado para produzir, praticar, desempenhar, ratificar sua positividade com aspectos de sua subjetividade e sociabilidade frente aos outros por meio de multitarefas, tudo ao 
mesmo tempo. Han (2015) mostra que isso só pode resultar em frustações e sofrimento em exigir tanto do eu, surgindo assim à sociedade do cansaço. Formada pelas transformações da sociedade ativa e do desempenho geram um cansaço e esgotamento em excessos, em que não há uma separação, mas de continuidade de produção.

O excesso de positividade se manifesta também como excesso de estímulos, informações e impulsos. Modifica radicalmente a estrutura e economia da atenção. Com isso se fragmenta e destrói a atenção. Também a crescente sobrecarga de trabalho torna necessária uma técnica específica relacionada ao tempo e à atenção, que tem efeitos novamente na estrutura da atenção (HAN, 2015, p. 31).

No capítulo I, “A violência neuronal”, Han traça um caminho para demonstrar que cada era tem suas enfermidades e expõe o fim de uma fase bacteriológica. Segundo o autor, o século passado foi imunológico, apresentando um decrescimento das enfermidades da época com o surgimento de técnicas imunológicas. Como forma de defesa e distanciamento, a era imunológica foi demarcada para erradicar tudo aquilo que era estranho ao outro, uma divisão de amigo e de inimigo, de dentro e de fora. Desta feita, no tecido social, a imunologia começa a perder espaço a partir do momento que o sujeito começa a perceber no outro, estrangeiro ou imigrante, um peso/fardo e não como uma ameaça, um inimigo em si.

A violência neuronal, citada pelo o autor, já não é mais originada do que é estranho, inicia-se pelo o excesso de positividade. Uma violência que se apesenta sem infecções generalizadas, mas sublinham pequenos enfartos, doenças neuronais, que ganham espaços como depressão, transtorno de déficit de atenção, Síndrome de Bounoult e Síndrome de Hiperatividade. Assim, a violência neuronal é diagnosticada pela positividade do sujeito, que transparecem em ações como a superprodução, a hiperatividade, o superdesempenho, além da facilidade da comunicação atual, a supercomunicação por meio de plataformas digitais. Destarte, em contraste da violência viral que foi marcada pela negatividade, em contradição com a positividade, a violência neuronal requer uma superesforço do sujeito em buscar mais de si, deixando-o saturado e esgotado, não permitindo-se ao fracasso, galga um caminho a beira da decadência e ruina psíquica.

No capítulo 2, "Além da sociedade disciplinar", o autor vem equiparando a sociedade do desempenho que está além da sociedade disciplinar caracterizada por Foucault (1987), passagem da era imunológica para patologia neuronal. Naquela sociedade caracterizada pela negatividade do não-ter- 
direito, têm como consequências dessa era, loucos, doentes e detentos, entres outras formas de subjetividade devido aos comportamentos do não-poder e da negação da normalidade aparente.

Dessa forma, sob a ótica do autor, a sociedade passou da negatividade para a positividade, do não poder para tudo posso e, consequentemente, da sociedade disciplinar para sociedade do desempenho. Com esse modelo social, os hospitais, os presídios, os asilos, os quartéis e as fábricas não pertencem mais à sociedade de hoje, dão lugar a shoppings centers, a academias, a bancos, os aeroportos e os laboratórios de genética que permitem escolher o descendente a luz da “perfeição". Nesse contexto, os indivíduos não se chamam mais sujeitos da obediência, mas sujeitos do desempenho e de superprodução. São considerados empresários de si mesmo. A lógica é empreender a si mesmo, produto de uma sociedade que constitui sujeitos subjetivos neoliberais.

Essa transição de uma sociedade para outra, conforme Foucault apresentou, mostra que a sociedade disciplinar não encaixou mais no ritmo social atual, com as mudanças econômicas, tecnológicas e comportamentais que ocorreram nas últimas décadas, forçando, de certa forma, uma adequação ou transformação à sociedade do desempenho, ou seja, um paradigma social, que no lugar de proibição, de impedimento, de mandamento ou de lei, entram em cena o projeto da iniciativa e da motivação. De certa forma, há passagem ou transformação do sujeito do dever para o sujeito do poder, em que a negatividade não é tão eficiente quanto à positividade do poder. Assim, o sujeito do desempenho se comporta de maneira bem mais produtiva, mais rápido e mais eficaz do que o sujeito da obediência.

Todo esse aceleramento e eficiência laboral, relacionado às sequelas que outrora, aparentemente, não eram evidentes, com destaque para o agravamento dos distúrbios da pisquê humano. Patologias do insucesso/fracasso do homem atual configura-se com a produção inúmeros sofrimentos psíquicos, oriundos do excesso de reponsabilidade motivada pela realização do desempenho esperado pelo novo modelo que a sociedade pós-moderna exige: sujeitos bem sucedidos e empresários de si mesmos. Todavia, são indivíduos esgotados, fracassados e depressivos, expressão patológica do fracasso do homem pós-moderno.

Agora os inimigos são outros, deixando de serem os diferentes, agora são neurais, ao invés do controle, temos agora uma sociedade do desempenho, carecendo do e no sujeito a sua própria 
gestão (autogestão e ilimitada para ação). Práticas que estão conduzindo para uma sociedade do doping, que gera um "desempenho sem desempenho" (HAN, 2015, p. 69).

O excesso de trabalho e desempenho agudiza-se numa auto-exploração. Essa é mais eficiente que uma exploração do outro, pois caminha de mãos dadas com o sentimento de liberdade. O explorador é ao mesmo tempo o explorado. Agressor e vítima não podem mais ser distinguidos. Essa autorreferencialidade gera uma liberdade paradoxal que, em virtude das estruturas coercitivas que lhe são inerentes, se transforma em violência. Os adoecimentos psíquicos da sociedade de desempenho são precisamente as manifestações patológicas dessa liberdade paradoxal (HAN, 2015, p. 30).

No capitulo 3, "O tédio profundo", o autor tece um crítica convidando Benjamin (1977; 1982), Nietzsche (1967) e Paul Cézanne (s.d.) para sublinhar o comportamento do sujeito e o seu modo de relacionar. Com excessos de estímulos, informações e afazeres, o indivíduo perde a atenção e o foco, estando engajado em multitarefas, perde a sensibilidade do olhar contemplativo. Nesse sentido, o compara ao animal selvagem, com necessidades de sobrevivência, que se engaja em atividades múltiplas não podendo concentrar-se ou aprofundarse sua atenção, tornando a atenção rasa e deficiente. Nesse aspecto relacionado à vida selvagem, Han sintetiza a falta de um processo criativo, uma inquietação que não gera nada de novo, mesmo com as diversas interaçoes nas plataformas sociais/digitais, ainda assim, é raso e superficial.

No quarto capítulo, "Vita activa", Han faz referência a Hanna Arendt (198I), trazendo o conceito do animal laborans e construindo um elo que caracteriza a sociedade atual com ações reduzidas ao trabalho. Sujeitos, que de certa maneira, dispersa formas de vida activa, cedendo lugar para a superprodução e para a hiperatividade. Todavia, a autora destaca que o animal laborans apresentado, está limitado ao nível/patamar do trabalho, fazendo com o indivíduo laborans ignore a vida contemplativa.

Em contraste com essa perspectiva, Han não vê o sujeito com essa representatividade na sociedade do desempenho, pois ego do indivíduo sobressai-se ao ponto de quase dilacera-se. Assim, o sujeito não abandona seu ego para doar-se ao trabalho, mas que, diversas vezes, o labor pode estender ou invadir o ambiente de lazer ou espaço de casa. Portanto, o sujeito do desempenho, citado por Han, é tanto ativo como atento a si mesmo, além do trabalho, que na 
ausência do ser em relação à vida activa, nascem sentimentos como inquietações, nervosismos, ansiedades e angústias.

No quinto capítulo, "Pedagogia do ver", o autor reporta sobre a vida contemplativa, na qual presume uma pedagogia do ver citando Nietzsche (1967). Segundo este, precisamos de educadores para nos ensinar a ler, a pensar, a falar e a aprender. Para que isso aconteça, é necessário educar o olhar para uma atenção profunda e contemplativa com fins de preparação da índole do espírito. $\mathrm{O}$ não aprendizado desses aspectos podem suceder quaisquer ações de impulso ou descontrole psíquico e comportamental, que resulta numa do ser: doenças e sintomas de esgotamento do sujeito.

Portanto, Han sublinha que há uma ilusão em acreditar que quanto mais ativos somos, mais livres poderemos ser. Destarte, o aspecto da atividade pura nada mais faz além de prolongar o que já é existente. Nesse sentido, o autor faz menção à positivação da sociedade que enfraquece e vulnerabiliza sentimentos como angústia e luto. Dessa forma, potencializa a negatividade, estando como criadora do aspecto essencial para a contemplatividade. Assim, como características da sociedade atual, a hiperatividade se mostra de maneira vazia de ser, uma omissão de fazer e uma positividade vaga e superficial.

"O caso Bartleby”, sexto capítulo apresentado por Han, analisa um estudo de caso de uma sociedade enferma com características de uma era adoecida. Uma literatura que conta a história de Bartleby, que contém sintomas de patologias ligadas ao esgotamento (fisco e mental) oriundo da excessividade de sua atividade laboral, num ambiente hostil e com atmosfera sombria, corolário do indivíduo do desempenho numa sociedade da hiperatividade e da superprodução.

Em suma, o enredo nuclear passa em um escritório, no coração da metrópole, em meios a aborrecimentos e com elementos de melancolia. Dessa forma, os personagens são depressivos, angustiados e sofrem com distúrbios neuróticos causados pela excessividade laboral. Todavia, Bartleby segue o caminho oposto, mesmo estando além da sociedade disciplinar, com elementos de um sujeito da obediência, tem um final frio: morre disperso e isolado. Assim, em meio a tanto movimento e inquietação, ele representa a ausência de iniciativa, de apatia e acaba sucumbindo- 
se. Portanto, Han nos mostra que quaisquer que sejam os esforços humanos em favor da vida, as ações sempre conduzem à morte.

Por fim, no capitulo 7, "A Sociedade do Cansaço" caracteriza uma sociedade do desempenho sem desempenho, ou seja, do doping cerebral. Destarte, a sociedade do desempenho e a sociedade ativa produzem cansaços e esgotamentos em excesso, devido ausência de negatividade, pois não sendo mais imunológico (atuando com o outro), se apresenta pela positividade, que com sua elevação do desempenho, conduz à solidão, ao isolamento e ao infarto da alma, um desempenho solitário e individualizado. Assim, o cansaço do esgotamento não se configura uma potência positiva, mas incapacita ao sujeito de realizar quaisquer atividades.

Portanto, Han apresenta uma análise da sociedade atual que não está vinculada a sociedade disciplinar, com normas, ordens, obrigações, ou seja, não a negativação das proibições. Todavia, mostra uma sociedade que aparenta ser livre, no qual o dever cedeu lugar para o poder e a negação foi substituída pela positividade e liberdade. Entretanto, essa liberdade traz uma coercitividade à superprodução, ou seja, tudo tornar-se possível por meio do esforço individual, solitário e vazio. Destarte, na sociedade neoliberal, busca-se potencializar a exigência do desempenho máximo do indivíduo, o qual vive uma incessante busca pela produtividade perfeita, onde "o excesso de trabalho e desempenho agudiza-se numa autoexploração" (HAN, 2015, p. 30). Nesse sentido, Han (2015) informa que a sociedade do cansaço existe pela ausência ou falta de repouso e que a civilização, caminha para uma nova barbárie (Nietzsche apud HAN, 2015), se apresentando o "imperativo do desempenho como um novo mandato da sociedade pósmoderna do trabalho" (HAN, 2015, p. 27).

Desse modo, a sociedade do desempenho e do trabalho (HAN, 2015), faz com que o sujeito seja prisioneiro de si, resultando o surgimento de repressões ou coerções.

A dialética de senhor e escravo está, não em última instância, para aquela sociedade na qual cada um é livre e que seria capaz também de ter tempo livre para o lazer. Leva ao contrário a uma sociedade do trabalho, na qual o próprio senhor se transformou num escravo do trabalho. Nessa sociedade coercitiva, cada um carrega consigo seu campo de trabalho. A especificidade desse campo de trabalho é que somos ao mesmo tempo prisioneiro e vigia, vítima e agressor. Assim, acabamos explorando a nós mesmos" (HAN, 2015, p. 47). 
Portanto, Han (2015) descarta a crença de que quanto mais ativos somos, mais livres seremos, ou seja, "uma ilusão acreditar que quanto mais ativos nos tornamos tanto mais livres seríamos" (2015, p. 52). Neste pensamento, o autor expõe que a hiperatividade na qual é uma característica da sociedade atual, tem aspecto de forma vazia do ser, uma omissão do fazer, um transtorno à liberdade, uma positividade vazia e sem sentido.

O sujeito de desempenho está livre da instância externa de domínio que o obriga a trabalhar ou que poderia explorá-lo. É senhor e soberano de si mesmo. Assim, não está submisso a ninguém ou está submisso apenas a si mesmo. É nisso que ele se distingue do sujeito de obediência. A queda da instância dominadora não leva à liberdade. Ao contrário, faz com que liberdade e coação coincidam. Assim, o sujeito de desempenho se entrega à liberdade coercitiva ou à livre coerção de maximizar o desempenho (HAN, 2015, p. 29-30).

Han (2015) nos diz que quando se consegue deixar o eu sozinho, não sobra mais nada, só o eu, único, sozinho, num cansaço psíquico fadado ao sofrimento e solidão, gerados por essa violência da busca incessante de ganhos. Muitas vezes ganhos não factíveis à sua realização, desencadeiam patologias neurais, surgimento de doenças difíceis de serem tratadas, como depressão ou outros distúrbios neurais causados pela força do desempenho, que resultam em esgotamentos neurais, originadas dessas exigências da positividade, uma exaustão do eu tentando ser o eu-eficiente.

Em decorrência disso, Han (2015, p. 7I) diz que o "excesso da elevação do desempenho leva a um infarto da alma. O cansaço da sociedade do desempenho é um cansaço solitário que atua individualizando e isolando" o indivíduo, o aprisionando no seu eu.

Evidencia-se que a questão da liberdade neoliberal, Han (2015) nos adverte sobre esta crise do homem em se libertar de si mesmo. Na dinâmica imposta pela na sociedade do cansaço, a demonstração de culpabilidade do eu, pode ser causada por querer ou estar presos ao sistema e ao processo da sociedade do desempenho. Um dos os aspectos que o homem pós-moderno tem enfrentado e que tem passado despercebido, tem a haver com a liberdade. Vista como liberdade prisionária, com insucesso do individuo que "fracassa na sociedade neoliberal do desempenho, em vez de questionar a sociedade ou o sistema, considera a si mesmo como responsável e se envergonha por isso" (HAN, 2018, p. 16). 
A liberdade para Han (2015) aparece e age de forma reversa, o sujeito que tem o senso de ser livre, entende-se que nunca está consciente de sua dependência e submissão ao sistema. Sendo submetida, a liberdade provoca "coerção" e, também, um servo absoluto. Ser senhor e escravo, ser chefe de si. Entra na ilusão de fazer seu horário, és livre, que "cada um é um trabalhador que explora a si mesmo para a sua própria empresa. Cada um é senhor e servo em uma única pessoa" (HAN, 2018, p. I4).

A literatura descreve com maestria os efeitos da sociedade do desempenho resultando numa sociedade do cansaço. Nesta, têm gerado culpas, sofrimentos, frustações e decepções. Desse modo, o adoecimento aparece como uma das poucas saídas possíveis, levando-o ao fracasso social e unitário.

Neste sentido, o sujeito do desempenho está em uma constante e crescente, os resultados, as cobranças e as exigências só podem originar um cansaço psíquico, um esgotamento que desencadeia doenças com grau de dificuldade latente para serem superadas. Uma vez que, na sociedade do desempenho os indivíduos estão fadados ao fracasso, a falhas e a derrotas solitárias, surgindo assim, uma sociedade do cansaço.

\section{REFERÊNCIA BIBLIOGRÁFICA}

HAN, Byung-Chul. Sociedade do cansaço. Tradução de Enio Paulo Giachini. Petrópolis - RJ: Vozes, 2015. 8o p. ISBN: 978-85-326-4996-6 (Brasil). 